\title{
Cyclocarya paliurus Polysaccharide Inhibits Glioma Cell U251 Proliferation, Migration, and Invasion and Promotes Apoptosis via the GSK3 $\beta / \beta$-Catenin Signaling Pathway
}

\author{
Xiaolong Du, Kai Guo, Yongqian Ma, and Jianyong Chang \\ Department of Neurosurgery, Weifang People's Hospital, Weifang, Shandong, China 261000 \\ Correspondence should be addressed to Jianyong Chang; changjy82@126.com
}

Received 23 December 2019; Revised 2 February 2020; Accepted 27 February 2020; Published 17 March 2020

Guest Editor: Can Yang Zhang

Copyright (C) 2020 Xiaolong Du et al. This is an open access article distributed under the Creative Commons Attribution License, which permits unrestricted use, distribution, and reproduction in any medium, provided the original work is properly cited.

\begin{abstract}
Objective. To investigate the effects of Cyclocarya paliurus polysaccharide (CPP) on the proliferation, migration, invasion, and apoptosis of human glioma U251 cells and further explore the underlying mechanism. Methods. U251 cells were cultured in vitro and treated with various concentrations $(25,50,75,100,125$, and $150 \mu \mathrm{mol} / \mathrm{L})$ of $\mathrm{CPP}$ for 24,48 , and $72 \mathrm{~h}$. Cell counting kit- 8 was used to detect the activity of cell proliferation. Wound-healing assay, Transwell assay, and flow cytometry were used to measure the effects of CPP on the migration, invasion, and apoptosis of U251 cells, respectively. Western blotting was used to determine the protein expression involved in the GSK3 $\beta / \beta$-catenin signaling pathway and its downstream genes related to proliferation, migration, invasion, and apoptosis including Cyr61, CCND1, Vimentin, and Slug. Meanwhile, qRT-PCR was used to detect the mRNA levels of Cyr61, CCND1, Vimentin, and Slug. Results. We found that CPP not only could inhibit the proliferation, migration, and invasion of U251 cells but also promote its apoptosis in vitro. Besides, CPP could significantly inhibit the phosphorylation and decrease the protein levels of GSK3 $\beta$ at ser9 site $(p<0.05)$, and thus increasing the phosphorylation of $\beta$-Catenin at ser33/37 site $(p<0.05)$, resulting in $\beta$-Catenin degradation. In addition, we also found that CPP could downregulate the mRNA $(p<0.05)$ and protein expression $(p<0.05)$ of downstream genes of GSK3 $\beta / \beta$-catenin signaling pathway including Cyr61, CCND1, Vimentin, and Slug, which are related to proliferation, migration, invasion, and apoptosis. Conclusion. CPP could inhibit the expression of GSK3 $\beta$, promote the degradation of $\beta$-catenin, and downregulate the levels of GSK3 $\beta / \beta$-catenin downstream genes including Cyr61, CCND1, Vimentin, and Slug, which regulate the proliferation, migration, invasion, and apoptosis of glioma cells.
\end{abstract}

\section{Introduction}

Glioma is one of the most aggressive malignant brain cancers, accounting for approximately $36 \%$ of primary brain tumors [1]. Glioma originates from glial cells and accounts for about $80 \%$ of malignant tumors of the central nervous system [2]. Although gliomas have a lower incidence than other cancers, gliomas have a relatively high mortality rate due to their highly invasive growth characteristics [3]. At present, despite the advances in treatment over the past decade, there is still no effective cure [4]. Chemotherapy is an important method for the treatment of gliomas. It can kill residual tumors that cannot be removed by surgery and radiotherapy. Therefore, it is of great significance to research the antiglioma drugs.

Cyclocarya paliurus is a plant of the genus Chrysanthemum (Jugaceae), mainly distributed in southern China. Its branches and leaves are sweet, having a cooling effect, and can reduce swelling and pain [5]. Modern pharmacological studies have shown that Cyclocarya paliurus contains a variety of nutrients and can play different biological roles [6]. Among these bioactive ingredients, Cyclocarya paliurus polysaccharide (CPP) is an important active ingredient. CPP and its complexes play critical roles in antitumor, anti-inflammatory, antiviral, antiaging, and anticoagulation [7-11]. Recent researches on CPP have mainly focused on its anticancer 
effect. For instance, Jin et al. reported that the combination of CPP and X-rays had significant proliferation inhibition and proapoptotic effects on SW480 colorectal cancer cells [12]; Zhang et al. found that CPP could increase the sensitivity of hypoxic A549 and H520 human non-small-cell lung cancer cells to radiotherapy. These studies show the potential of CPP as a chemotherapeutic agent for clinical tumor treatment [13]. However, there is currently no article on the role of CPP in gliomas, so this study will use the glioma cell line U251 for the first time to study the role of CPP in cell proliferation, migration, and invasion.

\section{Material and Methods}

2.1. Extraction and Identification of CPP. Crude polysaccharides were extracted from the leaves of Cyclocarya paliurus by water extraction and alcohol precipitation method, deproteinized by Sevag method, and dried by water dialysis. After that, the crude polysaccharide was purified using a D301R column and eluted with the $0.4 \mathrm{~m}$ aqueous solution of sodium chloride [11]. The extracted CPP was identified by the ultraviolet spectrum and infrared spectrum.

2.2. Determination of Molecular Weight and Analysis of Monosaccharide Components. The molecular weight of CPP was determined by high-performance liquid chromatography (1100, Agilent, USA). The system was equipped with SHODEX KS-802 and KS-804 columns $(7.8 \mathrm{~mm} \times 300 \mathrm{~mm})$, and a refractive index detector was used and the sample input was $20 \mu \mathrm{L}$. The sample was eluted with a $\mathrm{NaCl}$ aqueous solution $(0.2 \mathrm{~m})$ as a mobile phase at a flow rate of $0.8 \mathrm{ml} / \mathrm{min}$, and the column temperature was maintained at $40^{\circ} \mathrm{C}$. A series of standard dextran with known molecular weight values was used as the calibration curve, and the molecular weight was analyzed by Agilent-GPC software. A qq7000 capillary column $(30 \mathrm{~m} \times 0.25 \mathrm{~mm} \times 0.25 \mathrm{~m}$, Agilent, USA $)$ and a hydrogen ionized flame detector (FID) were used in the gas chromatography analysis of monosaccharides in CPP. Specifically, the dried CPP $(2.0 \mathrm{mg})$ was dissolved in $1.0 \mathrm{ml}$ TFA $(2.0 \mathrm{M})$, hydrolyzed in an ampule at $120^{\circ} \mathrm{C}$ for $90 \mathrm{~min}$, washed with methanol, and then evaporated to remove TFA. The hydrolysate was reduced with $\mathrm{NaBH} 4$ and acetylated with ethyl acetate at $100^{\circ} \mathrm{C}$ for $60 \mathrm{~min}$, and then, the acetic anhydride was destroyed with ice water. The obtained alditol was extracted with chloroform, and the resultant was analyzed by gas chromatography. The gas chromatography analysis procedure was as follows: injection temperature: $250^{\circ} \mathrm{C}$; detector temperature: $250^{\circ} \mathrm{C}$; column temperature increased from $120^{\circ} \mathrm{C}$ to $250^{\circ} \mathrm{C}$, with an increasing rate of $3^{\circ} \mathrm{C} / \mathrm{min}$, and finally maintained at $250^{\circ} \mathrm{C}$ for 5 minutes. Nitrogen was used as the carrier gas and maintained at $1 \mathrm{~mL} / \mathrm{min}$. Air and hydrogen velocities were 400 and $30 \mathrm{~mL} / \mathrm{min}$, respectively. Seven monosaccharides were used as reference materials to quantitatively determine the monosaccharide content of CPP.

2.3. Cell Culture. Human glioma cells U251 were purchased from ATCC, USA. U251 cells were routinely cultured using DMEM medium (Thermo Fisher Scientific Inc., China) con- taining $10 \%$ fetal bovine serum (Gibco, USA), $100 \mathrm{U} / \mathrm{mL}$ penicillin, and $100 \mathrm{~g} / \mathrm{mL}$ streptomycin (Gibco, USA). The temperature of the humidified incubator was maintained at $37^{\circ} \mathrm{C}$ and contained 5\% carbon dioxide. Experiments were performed using only cells in the exponential growth phase.

2.4. Cell Counting Kit-8 (CCK-8) Detects Cell Proliferation Activity. U251 cells were seeded at a density of $5 \times 10^{3}$ cells/well in a 96-well plate and cultured overnight. The next day, CPP of different concentrations (25, 50, 75, $100,125$, and $150 \mu \mathrm{mol} / \mathrm{L})$ prepared with cell culture medium [14] was added. For the control group, $10 \mu \mathrm{L}$ CCK-8 reagent (Dojindo, Japan) was added per well at 24,48 , and $72 \mathrm{~h}$. After a certain period of incubation, the absorbance $(A)$ at $450 \mathrm{~nm}$ was measured on a spectrophotometer. The relative cell activity (\%) is calculated as relative cell activity $(\%)=(A($ experimental group $)-A($ blank group $)) /(A$ (control group) - $A$ (blank group) $)$.

2.5. Cell Scratch Test to Assess Cell Migration Ability. U251 cells were seeded in a 12 -well plate and cultured overnight. The next day, cells were treated with CPP at different concentrations and cultured until the cell fusion rate reached 95\%. A sterile $100 \mu \mathrm{L}$ pipette tip was used to draw a straight line on the monolayer cells, then the cells were washed with PBS. After that, 1\% FBS DMEM medium and different concentrations of CPP were added. $24 \mathrm{~h}$ later, the cells that migrated to the injured area were observed and photographed under an inverted microscope.

2.6. Cell Invasion Assay to Detect Cell Invasion. For the cell invasion test, the upper chamber of the Transwell chamber (Corning, USA) was coated with a mixture containing $100 \mu \mathrm{L}$ of Matrigel (Corning, USA) and serum-free DMEM medium. After the Matrigel coagulated, cells with certain density were seeded into the upper chamber of DMEM without FBS, and at the same time, DMEM medium containing $10 \%$ fetal bovine serum was added to the lower chamber. After $24 \mathrm{~h}$ incubation at $37^{\circ} \mathrm{C}$, the invading cells were fixed with $20 \%$ methanol and stained with $0.1 \%$ crystal violet. The cells were photographed and counted under a microscope.

2.7. Detection of Apoptosis by Flow Cytometry. U251 cells were seeded in 6-well plates and incubated overnight. The next day, each well was added with different concentrations of CPP and cultured in an incubator for $72 \mathrm{~h}$. The cells were collected, centrifuged, and washed according to the instructions of the flow cytometry kit (Biyuntian, China). $5 \mu \mathrm{L}$ of Annexin V (fluorescein isothiocyanate) was added to the cell suspension and incubated for 15 minutes under the light. $10 \mu \mathrm{L}$ of propidium iodide (PI) was added for double staining and incubated for 5 minutes in the dark. The analysis was performed within $1 \mathrm{~h}$ after the incubation.

2.8. Western Blotting Method to Determine Cell Protein Expression Level. After the cells were extracted with RIPA strong lysate (Biyuntian, China), the protein was quantified by the BCA method. $50 \mu \mathrm{g}$ of the protein sample was loaded on the 10\% SDS-PAGE electrophoresis gel, and Western blotting was carried out on a PVDF membrane (Invitrogen, 


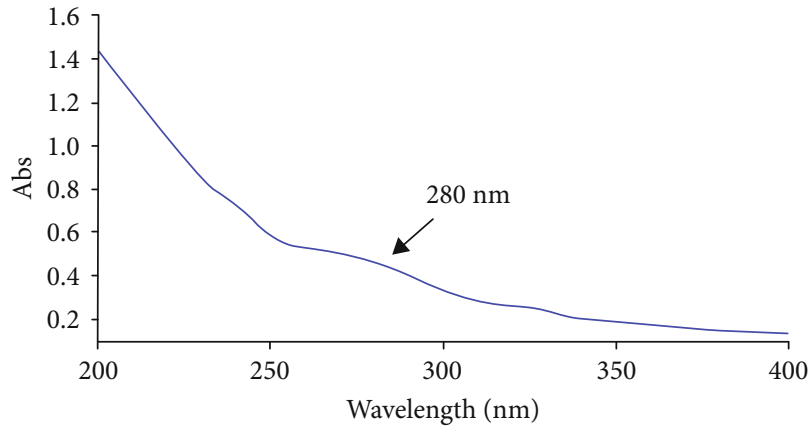

(a)

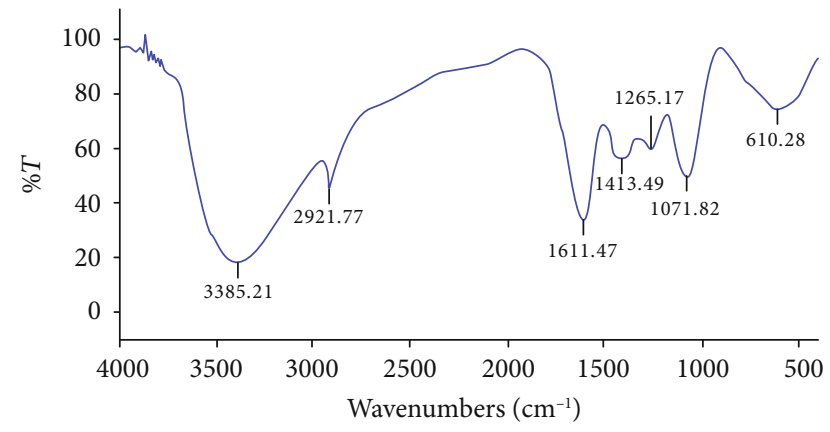

(b)

Figure 1: Identification of CPP in polysaccharides. (a) Ultraviolet spectrum identification result of CPP; (b) infrared spectrum identification result of CPP.

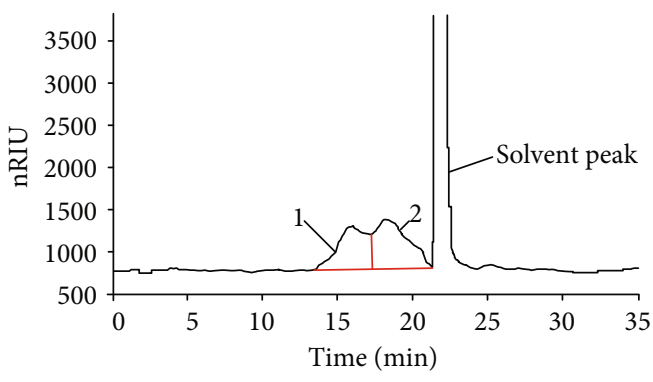

(a)

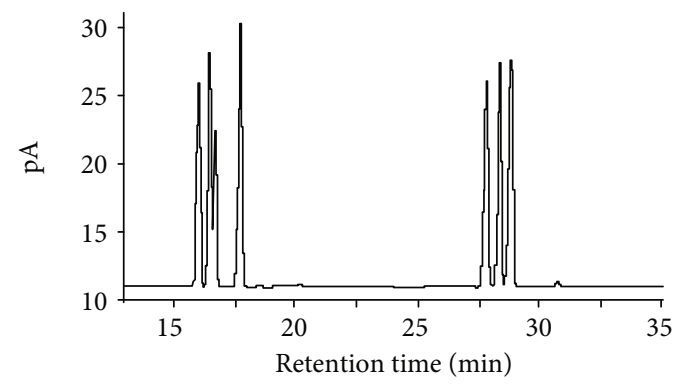

(b)

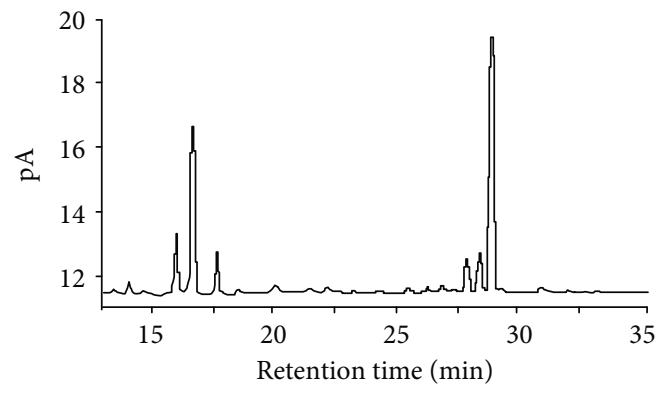

(c)

FIGURE 2: Molecular weight and gas chromatography analysis of CPP. (a) High-performance liquid chromatogram, (b) gas chromatogram of monosaccharide standard, and (c) gas chromatogram of CPP monosaccharide.

USA). The membrane was blocked at room temperature, washed with TBST after blocking, and primary antibody reaction solution including p-GSK3 $\beta$ (Ser9, ab131097, Abcam, USA), GSK3 $\beta$ (ab93926, Abcam, USA), p- $\beta$-catenin (Ser33/37, Ab11350, Abcam, UK), $\beta$-catenin (ab16051, Abcam, USA), Cyr61 (ab24448, Abcam, USA), CCDN1 (ab134175, Abcam, USA), Vimentin (ab8978, Abcam, USA), Slug (ab51772, Abcam, USA), and $\beta$-actin (ab179467, Abcam, USA) was added and incubated overnight at $4^{\circ} \mathrm{C}$. The corresponding HRP-conjugated secondary antibody was added and incubated at room temperature after TBST elution. The image was then developed on the ECL luminescence imaging system.

2.9. Detection of $m R N A$ Expression by Real-Time Fluorescent Quantitative PCR ( $q P C R)$. Total cellular RNA was extracted using TRIzol reagent (Invitrogen, USA). RNA concentration and purity were then measured spectrophotometrically and reversely transcribed (Takara, Japan) into cDNA. SYBR Green PCR Master Mix (Takara, Japan) was used for PCR amplification (Applied Biosystems, USA), $\beta$-actin was used as the housekeeping gene, and the relative expression of Cyr61, CCND1, Vimentin, and Slug mRNA was calculated using the $2^{-\Delta \Delta \mathrm{Ct}}$ method. Experiments were repeated 3 times independently.

The primer sequences are as follows: Cyr61 preprimer $\left(5^{\prime}\right.$ $\left.-3^{\prime}\right)$ : AGCAGCCTGAAAAAGGGCAA, postprimer $\left(5^{\prime}-3^{\prime}\right)$ : AGCCTGTAGAAGGGAAACGC; CCND1 preprimer $\left(5^{\prime}\right.$ $\left.-3^{\prime}\right)$ : GCTGCGAAGTGGAAACCATC, postprimer $\left(5^{\prime}-3^{\prime}\right)$ : CCTCCTTCTGCACACATTTGAA; Vimentin preprimer $\left(5^{\prime}-3^{\prime}\right)$ : GACGCCATCAACACCGAGTT, postprimer $\left(5^{\prime}\right.$ $\left.-3^{\prime}\right)$ : CTTTGTCGTTGGTTAGCTGGT; Slug preprimer $\left(5^{\prime}\right.$ 


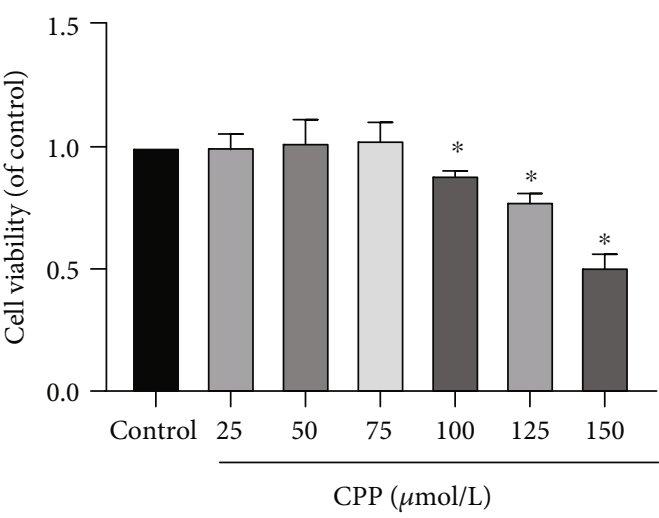

(a)

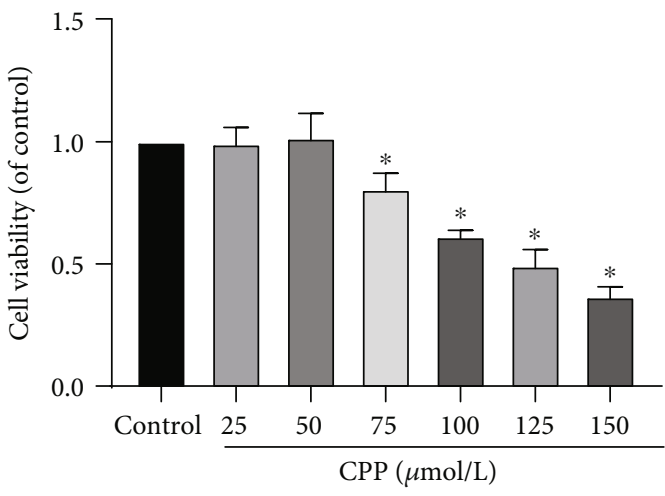

(b)

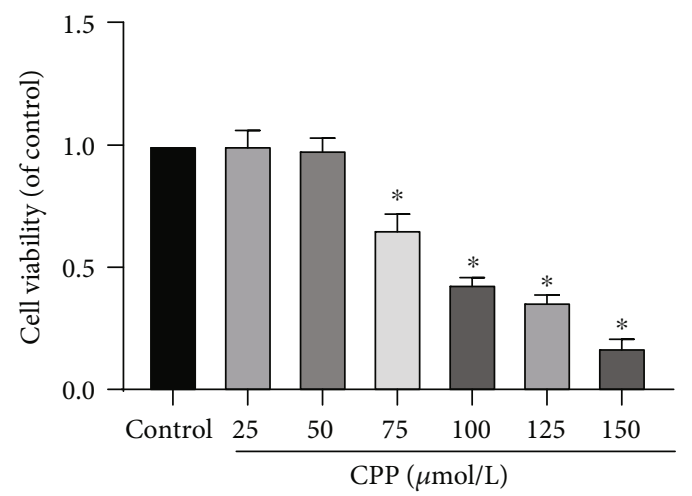

(c)

Figure 3: CPP inhibits U251 cell viability. (a-c) Changes in cell viability after 24,48 , and $72 \mathrm{~h}$ of CPP treatment $(25,50,75,100,125$, and $150 \mu \mathrm{mol} / \mathrm{L})$ at different concentrations. Compared with the control group, $*$ indicates $p<0.05$. This experiment was repeated three times independently.

$\left.-3^{\prime}\right)$ : CGAACTGGACACACATACAGTG, postprimer $\left(5^{\prime}\right.$ $\left.-3^{\prime}\right)$ : CTGAGGATCTCTGGTTGTGGT; and $\beta$-actin preprimer $\left(5^{\prime}-3^{\prime}\right)$ : CATGTACGTTGCTATCCAGGC, postprimer $\left(5^{\prime}-3^{\prime}\right)$ : CTCCTTAATGTCACGCACGAT.

2.10. Statistical Analysis. Experimental data were expressed as mean \pm standard deviation. Statistical analysis was performed using SPSS 18.0 software. Student's $t$-test was used for pairwise comparison of data between groups, and univariate analysis of variance was used for comparison within groups. $p<0.05$ was considered statistically significant.

\section{Results}

3.1. Isolation, Purification, and Structural Analysis of CPP. As shown in Figure 1(a), CPP had no absorption at $260 \mathrm{~nm}$, which indicates that there was no nucleic acid. The weak peak height at $280 \mathrm{~nm}$ was due to the presence of the protein, but whether the protein was a free protein or a dextran protein complex was not clear. The total sugar content of CPP determined by the phenol-sulfuric acid method was $62.4 \%$. As shown in the infrared spectrum of Figure 1(b), the broad peak at $3385.21 \mathrm{~cm}^{-1}$ and the weak absorption peak at $2921.77 \mathrm{~cm}^{-1}$ were due to the $\mathrm{C}-\mathrm{H}$ stretching of the $\mathrm{CH} 2$ group. The strong absorption peak at $1611.47 \mathrm{~cm}^{-1}$ was due
TABLE 1: U251 cell viability changes under different concentrations and time of CPP treatment.

\begin{tabular}{lccc}
\hline Groups & $24 \mathrm{~h}$ & $48 \mathrm{~h}$ & $72 \mathrm{~h}$ \\
\hline Control & 1 & 1 & 1 \\
$\mathrm{CPP} 25 \mu \mathrm{mol} / \mathrm{L}$ & $1.00 \pm 0.05$ & $0.99 \pm 0.07$ & $1.00 \pm 0.06$ \\
$\mathrm{CPP} 50 \mu \mathrm{mol} / \mathrm{L}$ & $1.02 \pm 0.09$ & $1.02 \pm 0.10$ & $0.98 \pm 0.05$ \\
$\mathrm{CPP} 75 \mu \mathrm{mol} / \mathrm{L}$ & $1.03 \pm 0.07$ & $0.81 \pm 0.07$ & $0.66 \pm 0.06$ \\
$\mathrm{CPP} 100 \mu \mathrm{mol} / \mathrm{L}$ & $0.89 \pm 0.02$ & $0.61 \pm 0.03$ & $0.43 \pm 0.03$ \\
$\mathrm{CPP} 125 \mu \mathrm{mol} / \mathrm{L}$ & $0.78 \pm 0.03$ & $0.49 \pm 0.07$ & $0.36 \pm 0.03$ \\
$\mathrm{CPP} 150 \mu \mathrm{mol} / \mathrm{L}$ & $0.51 \pm 0.05$ & $0.37 \pm 0.04$ & $0.17 \pm 0.03$ \\
\hline
\end{tabular}

Note: compared with the control group, ${ }^{*} p<0.05$.

to the $\mathrm{C}=\mathrm{O}$ asymmetric tensile vibration of the carboxylic acid group and wide absorption peaks at $1413.49 \mathrm{~cm}^{-1}$ were caused by the deformation vibration of hydrogen bonds. The three bands at 3400,2922 , and $1414 \mathrm{~cm}^{-1}$ were characteristic of polysaccharides. The $\mathrm{C}-\mathrm{O}-\mathrm{C}$ asymmetric tensile vibration band appeared at about $1265.17 \mathrm{~cm}^{-1}$, and the symmetrical tensile vibration appears at about $1071.82 \mathrm{~cm}^{-1}$.

As shown in Figure 2(a), CPP was mainly divided into two parts, namely, CPP-1 and CPP-2. The average molecular weight $(\mathrm{Mw})$ of CPP-1 was $1.32 \times 10^{5}$, the number average 

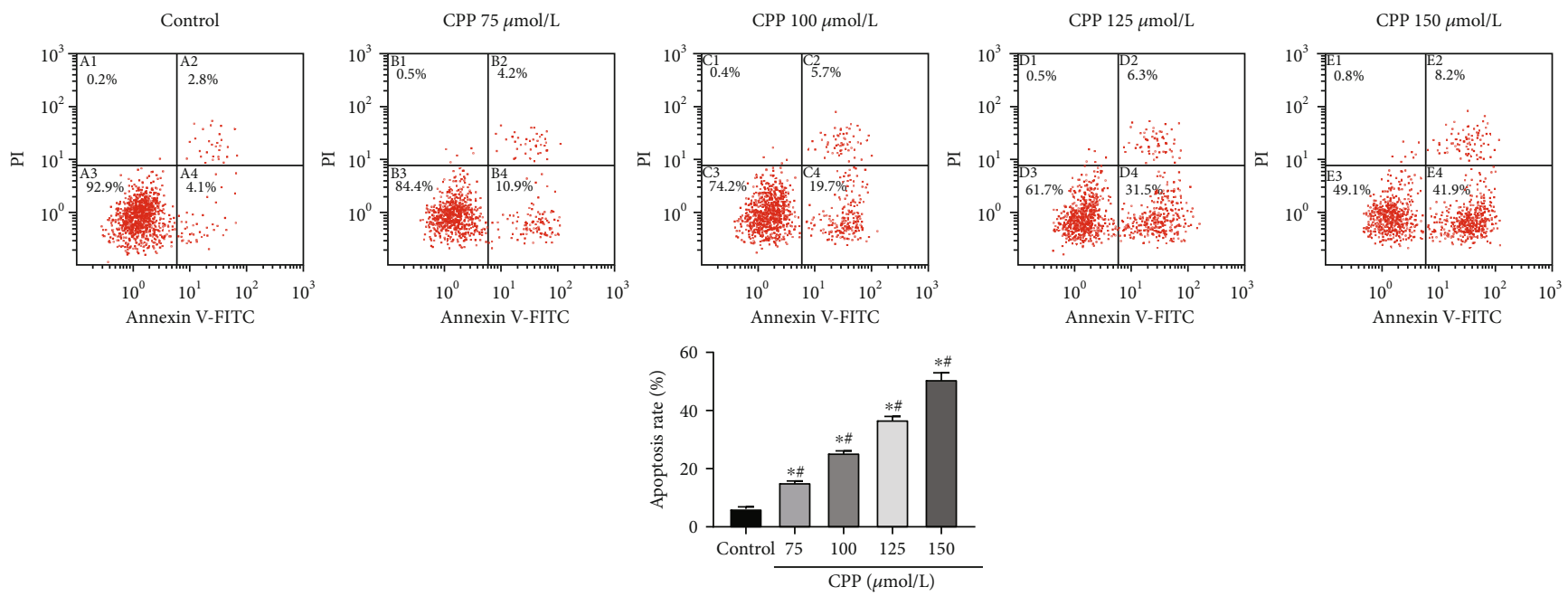

FIGURE 4: CPP induces apoptosis of U251 cells. Compared with the control group, $*$ indicates $p<0.05$. Comparison between treatment groups with different concentrations of $\mathrm{CPP}(75,100,125$, and $150 \mu \mathrm{mol} / \mathrm{L})$, \# indicates $p<0.05$. This experiment was repeated three times independently.

molecular weight $(\mathrm{Mn})$ was $9.83 \times 10^{4}$, the $Z$ average molecular weight $(\mathrm{Mz})$ was $1.97 \times 10^{5}$, the $\mathrm{Mw}$ of $\mathrm{CPP}-2$ was $9.31 \times 10^{3}$, the $\mathrm{Mn}$ was $5.41 \times 10^{3}$, and the $\mathrm{Mz}$ was $1.34 \times 10^{4}$. As shown in Figures 2(b) and 2(c), the following monosaccharides were separated by gas chromatography: rhamnose, fucose, arabinose, xylose, mannose, glucose, and galactose, with retention times of $15.921,16.383,16.63$, $17.662,27.687,28.228$, and $28.72 \mathrm{~min}$, respectively. The results showed that CPP was mainly composed of rhamnose, arabinose, xylose, mannose, glucose, and galactose, and the molar ratio was $1.00: 2.21: 0.62: 0.50: 0.62: 4.18$, indicating that the main component of CPP was galactose.

\subsection{CPP Reduces the Proliferation Activity of Human Glioma} Cell U251. As shown in Figure 3, compared with the control group, U251 cells had a dose-dependent decrease in cell activity after 24,48 , and $72 \mathrm{~h}$ of $25,50,75,100,125$, and $150 \mu \mathrm{mol} / \mathrm{L}$ CPP treatment $(p<0.05)$. When treated for $24 \mathrm{~h}$ with CPP (concentration was in the range of 25, 50, and $75 \mu \mathrm{mol} / \mathrm{L}$ ), compared with the control group, U251 cell viability did not change significantly at each time point $(p>0.05)$. When the CPP concentration reached $100 \mu \mathrm{mol} / \mathrm{L}$, cell viability was significantly reduced at all time points $(p<0.05)$. When treated with CPP (concentration was in the range of 25 and $50 \mu \mathrm{mol} / \mathrm{L}$ ) for 48 and $72 \mathrm{~h}$, compared with the control group, U251 cell viability did not change significantly at each time point $(p>0.05)$. When the CPP concentration reached $75 \mu \mathrm{mol} / \mathrm{L}$, cell viability was significantly reduced at all time points $(p<0.05)$. And the longer the treatment time, the higher the degree of cell viability reduction. The numerical changes of specific cell viability are shown in Table 1 . The above results suggest that CPP can inhibit the proliferation of U251 cells.

3.3. CPP Induces Apoptosis of U251 Cells. As shown in Figure 4, after U251 cells were treated with different concentrations of $\operatorname{CPP}(75,100,125$, and $150 \mu \mathrm{mol} / \mathrm{L})$ for $72 \mathrm{~h}$, com-
TABLE 2: Apoptosis of U251 cells under different concentrations of CPP treatment.

\begin{tabular}{lc}
\hline Groups & Apoptosis rate $(\%)$ \\
\hline Control & $6.17 \pm 0.70$ \\
CPP $75 \mu \mathrm{mol} / \mathrm{L}$ & $15.20 \pm 0.56^{* \#}$ \\
$\mathrm{CPP} 100 \mu \mathrm{mol} / \mathrm{L}$ & $25.40 \pm 0.70^{* \#}$ \\
$\mathrm{CPP} 125 \mu \mathrm{mol} / \mathrm{L}$ & $36.83 \pm 1.12^{* \#}$ \\
$\mathrm{CPP} 150 \mu \mathrm{mol} / \mathrm{L}$ & $50.67 \pm 2.30^{* \#}$ \\
\hline
\end{tabular}

Note: compared with the control group, ${ }^{*} p<0.05$. Comparison between treatment groups with different concentrations of CPP $(75,100,125$, and $150 \mu \mathrm{mol} / \mathrm{L}), \# p<0.05$.

pared with the control group, the apoptosis rate increased with the increase of CPP treatment concentration $(p<0.05)$, as detailed in Table 2. The results suggest that the administration of CPP to U251 cells can induce the occurrence of apoptotic responses.

3.4. CPP Treatment Reduces U251 Cell Migration Capacity. As shown in Figure 5, after treating U251 cells with different concentrations of CPP $(75,100,125$, and $150 \mu \mathrm{mol} / \mathrm{L})$ for $72 \mathrm{~h}$, compared with the control group, the cell migration ability of the CPP-treated group was significantly reduced $(p<0.05)$ in a dose-dependent manner $(p<0.05)$.

3.5. CPP Inhibits the Invasion of U251 Cells. As shown in Figure 6, when U251 cells were exposed to different concentrations $(75,100,125$, and $150 \mu \mathrm{mol} / \mathrm{L})$ of $\mathrm{CPP}$, their invasion capacity was significantly reduced $(p<0.05)$. With the increase of the CPP treatment concentration, the cell invasion capacity declined in a dose-dependent manner $(p<0.05)$.

3.6. CPP Inhibits Activation of the GSK3 $\beta / \beta$-Catenin Signaling Pathway. As shown in Figure 7, when U251 cells were treated with $150 \mu \mathrm{mol} / \mathrm{L}$ CPP for $72 \mathrm{~h}$, the Western 

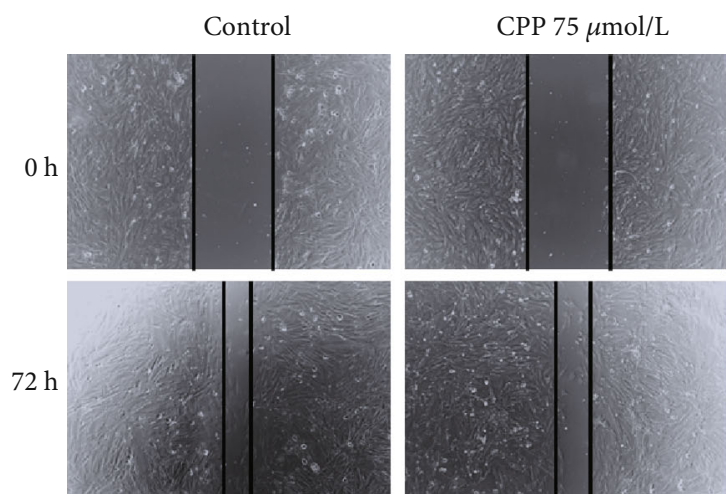

$\mathrm{CPP} 100 \mu \mathrm{mol} / \mathrm{L}$
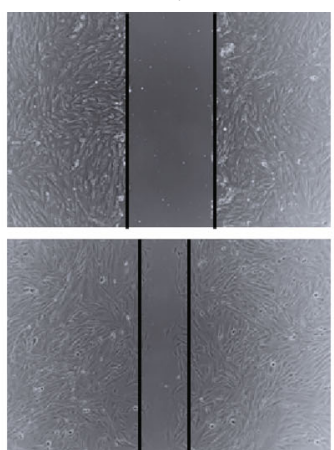

CPP $125 \mu \mathrm{mol} / \mathrm{L}$
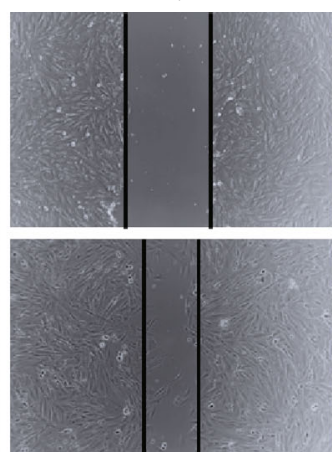

CPP $150 \mu \mathrm{mol} / \mathrm{L}$
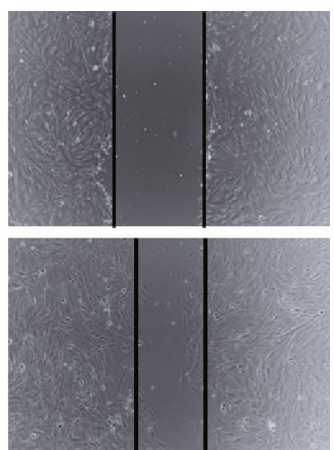

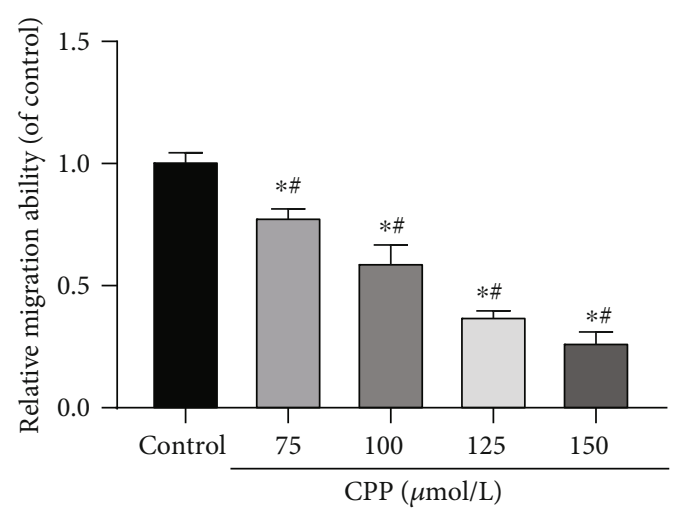

FiguRE 5: CPP treatment reduces U251 cell migration capacity. Compared with the control group, $*$ indicates $p<0.05$. Comparison between treatment groups with different concentrations of CPP $(75,100,125$, and $150 \mu \mathrm{mol} / \mathrm{L})$, \# indicates $p<0.05$. This experiment was repeated three times independently.

Control

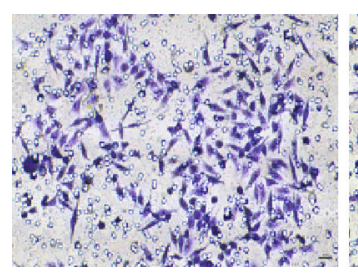

$\mathrm{CPP} 75 \mu \mathrm{mol} / \mathrm{L}$

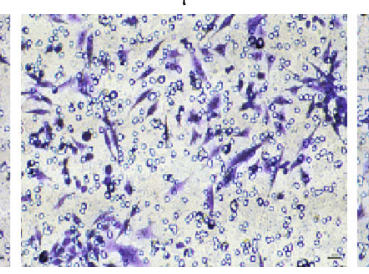

$\mathrm{CPP} 100 \mu \mathrm{mol} / \mathrm{L}$

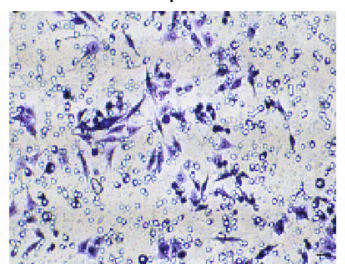

CPP $125 \mu \mathrm{mol} / \mathrm{L}$

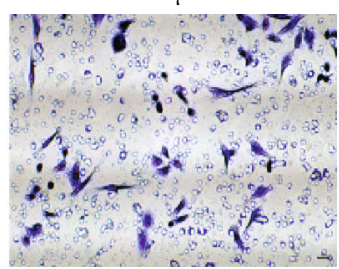

CPP $150 \mu \mathrm{mol} / \mathrm{L}$

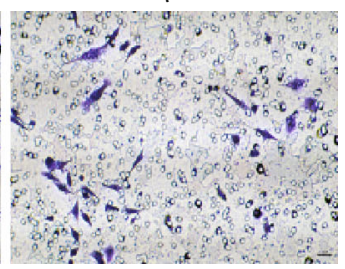

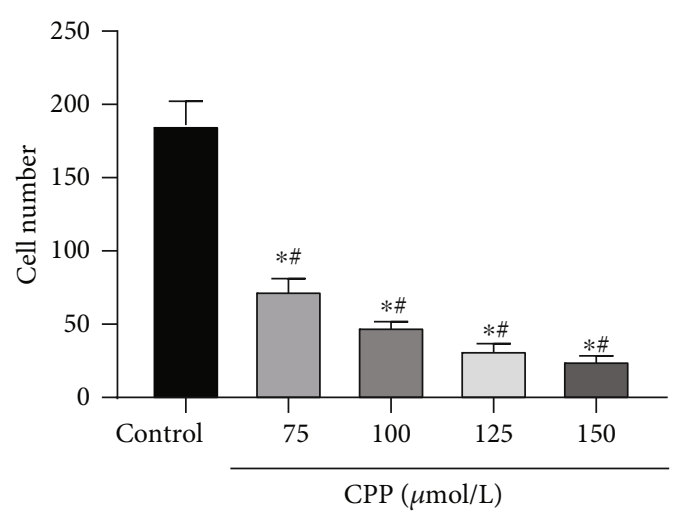

FIGURE 6: CPP treatment inhibits the invasion of U251 cells. Compared with the control group, $*$ indicates $p<0.05$. Comparison between treatment groups with different concentrations of $\operatorname{CPP}(75,100,125$, and $150 \mu \mathrm{mol} / \mathrm{L})$, \# indicates $p<0.05$. The experiment was repeated three times independently. 


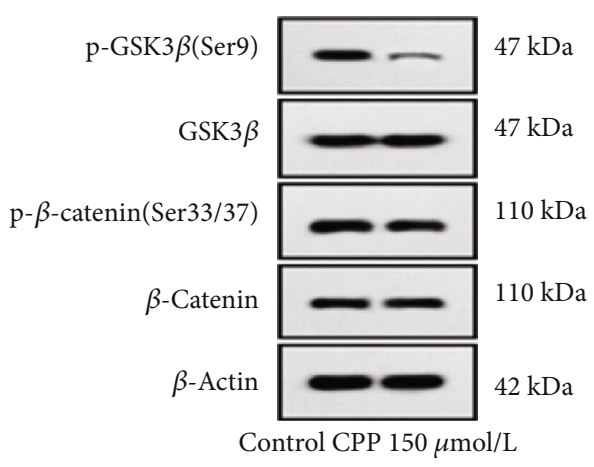

Figure 7: CPP inhibits GSK3 $\beta / \beta$-catenin signaling pathway activation. Compared with the control group, $*$ indicates $p<0.05$. This experiment was repeated three times independently.

blotting result showed that compared with the control group, CPP can significantly reduce the protein level of GSK3 $\beta$ and its phosphorylation level at Ser9 site. Furthermore, treatment with CPP promotes the phosphorylation level of $\beta$-catenin at Ser33/37 site, leading to the degradation of $\beta$-catenin.

3.7. CPP Inhibits the Expression of Oncogenes Downstream of the GSK3 $\beta / \beta$-Catenin Signaling Pathway. As shown in Figure 8, when U251 cells were treated with $150 \mu \mathrm{mol} / \mathrm{L}$ CPP for $72 \mathrm{~h}$, compared with the control group, the mRNA and protein levels of Cyr61, CCND1, Vimentin, and Slug (proliferation, apoptosis, migration, and invasion related genes downstream of SK $3 \beta / \beta$-catenin signaling pathway) were significantly reduced (all $p<0.05$ ).

\section{Discussion}

As an edible and medicinal plant, Cyclocarya paliurus is widely used in the treatment of various diseases $[15,16]$. The polysaccharide is the main active ingredient of Cyclocarya paliurus [14]. Polysaccharides, as natural biological macromolecules, have a variety of biological activities and are closely related to the maintenance of biological processes, for example, fungi and Ganoderma, which have inhibitory effects on tumor cells $[17,18]$. There are few studies on the antitumor effect of CPP. This study found that CPP can play a positive role in the treatment of gliomas by inhibiting the activation of GSK $3 \beta / \beta$-catenin signaling pathway and inhibiting the downstream gene expression related to proliferation, apoptosis, migration, and invasion.

Previous studies have confirmed that in colorectal cancer cells, CPP can work in combination with X-rays to inhibit the PI3K/Akt signaling pathway, thereby playing a role in inhibiting cancer cell proliferation and promoting apoptotic responses [12]; in addition, it has been found that CPP can increase the sensitivity of human non-small-cell lung cancer to radiotherapy [11], mainly by inhibiting the activation of the mTOR/Akt/PI3K signaling pathway. As there is no research report on CPP in glioma, we found for the first time in this study that CPP has a significant inhibitory effect on glioma, suggesting that CPP is expected to play a positive role in the clinical treatment of glioma.

GSK $3 \beta$ is a serine-threonine kinase that can regulate signaling pathways involved in cell proliferation and cell cycle $[19,20]$. Furthermore, GSK3 $\beta$ also participates in tumorigenesis through $\mathrm{Wnt} / \beta$-catenin. Studies have found that inhibition of GSK3 $\beta$ can induce cell death in gliomas [21]. GSK3 $\beta$ activity depends on its phosphorylation of serine 9 . Under normal conditions, GSK3 $\beta$ is nonphosphorylated and active. GSK3 $\beta$ phosphorylation can interact with $\beta$ catenin and cause $\beta$-catenin degradation [22]. Conversely, if $\beta$-catenin degradation is inhibited, activation of oncogene can occur. Consistent with previous reports, this study confirms that CPP can inhibit the phosphorylation and protein levels of GSK $3 \beta$ at Ser9, thereby promoting the phosphorylation of $\beta$-catenin at Ser33/37, leading to the degradation of $\beta$ catenin and thus inhibiting GSK $3 \beta / \beta$-catenin signaling pathway activation.

At the same time, after we found that CPP can inhibit the proliferation, migration, and invasion of glioma cells through CCK-8, cell scratches, and Transwell experiments, we further investigated the mRNA expression and protein levels of oncogenes downstream of GSK $3 \beta / \beta$-catenin signaling pathway including Cyr61, CCND1, Vimentin, and Slug which are related to proliferation and migration. Cyr61 is a cysteine-rich, secreted, heparin-binding protein that can participate in a variety of cellular functions such as adhesion, migration, and proliferation [23]. Previously, Xie et al. reported that compared with normal brain tissue, Cyr61 is highly expressed in 66 cases of primary glioma, and Cyr61 expression is significantly related to tumor grade and patient survival [24]; CCND1, as an oncogene [25], is highly expressed in glioma, breast, and bladder cancer; the expression level of CCND1 is related to the malignant degree of tumors and has the effect of regulating the growth and proliferation of cancer cells [26]; Vimentin can reduce the expression of cell surface adhesion factors, thereby promoting the occurrence of cell migration and invasion. It is highly expressed in a variety of cancer tissues, especially in cancers with metastasis [27]; Slug originated from the neural crest and has been reported to be involved in regulating tumor cell invasion, migration, cell cycle, and other activities [28]. In this study, qPCR and Western blotting experiments were performed to demonstrate that CPP treatment of U251 can cause the downregulation of mRNA and protein expression levels of Cyr61, CCND1, Vimentin, and Slug to different degrees, suggesting that CPP plays critical roles in regulating the proliferation, apoptosis, migration, and invasion of gliomas through inhibiting the expression of GSK $3 \beta / \beta$ catenin downstream oncogenes Cyr61, CCND1, Vimentin, and Slug.

In this study, crude polysaccharides were first extracted from the leaves of Cyclocarya paliurus, and CPP was obtained after purification and drying. Through a series of in vitro experiments based on glioma cells U251, it was found that CPP has a certain cytotoxic effect to inhibit cell proliferation, apoptosis, migration, and invasion. In addition, in the mechanism research, we also found that CPP can inhibit the 


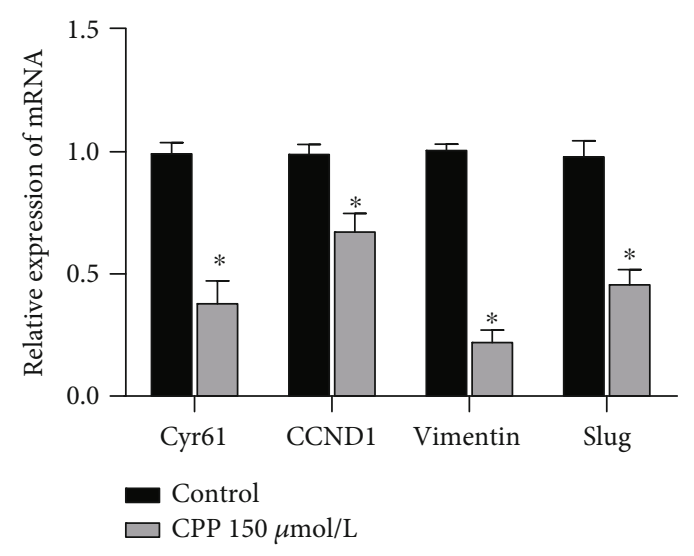

(a)

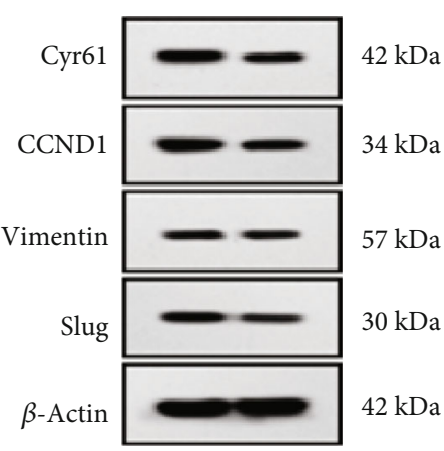

(b)

FIGURE 8: CPP inhibits the expression of oncogenes downstream of the GSK3 $\beta / \beta$-catenin signaling pathway. Compared with the control group, $*$ indicates $p<0.05$. This experiment was repeated three times independently.

activation of GSK3 $\beta / \beta$-catenin signaling pathway. Furthermore, through the inhibition of the GSK $3 \beta / \beta$-catenin signaling pathway, CPP can reduce the expression level of proliferation, apoptosis, migration, and invasion related genes such as Cyr61 and CCND1. All these results indicate that CPP may play a protective role in the treatment of gliomas, which deserves further study.

\section{Data Availability}

All the data is available with the handwritten notebook documented in our lab.

\section{Conflicts of Interest}

The authors declare that there are no conflicts of interest regarding the publication of this paper.

\section{Acknowledgments}

This work is supported by Weifang Science and Technology Development Plan Project (Grant no. 2019YX040).

\section{References}

[1] L. Ryskalin, A. Gaglione, F. Limanaqi et al., "The autophagy status of cancer stem cells in gliobastoma multiforme: from cancer promotion to therapeutic strategies," International Journal of Molecular Sciences, vol. 20, no. 15, p. 3824, 2019.

[2] C. H. Xu, L. M. Xiao, Y. Liu et al., "The lncRNA HOXA11-AS promotes glioma cell growth and metastasis by targeting miR-130a-5p/HMGB2," European Review for Medical and Pharmacological Sciences, vol. 23, no. 1, pp. 241-252, 2019.

[3] R. L. Siegel, K. D. Miller, and A. Jemal, "Cancer statistics, 2017," CA: a Cancer Journal for Clinicians, vol. 67, no. 1, pp. 7-30, 2017.

[4] M. N. A. Kamarudin and I. Parhar, "Emerging therapeutic potential of antipsychotic drugs in the management of human glioma: a comprehensive review," Oncotarget, vol. 10, no. 39, pp. 3952-3977, 2019.
[5] Q. Li, J. Hu, J. Xie, S. Nie, and M. Y. Xie, "Isolation, structure, and bioactivities of polysaccharides from Cyclocarya paliurus (Batal.) Iljinskaja," Annals of the New York Academy of Sciences, vol. 1398, no. 1, pp. 20-29, 2017.

[6] Z. J. Wang, J. H. Xie, M. Y. Shen et al., "Carboxymethylation of polysaccharide from Cyclocarya paliurus and their characterization and antioxidant properties evaluation," Carbohydrate Polymers, vol. 136, pp. 988-994, 2016.

[7] L. Xiong, K. H. Ouyang, Y. Jiang et al., "Chemical composition of _Cyclocarya paliurus_ polysaccharide and inflammatory effects in lipopolysaccharide-stimulated RAW264.7 macrophage," International Journal of Biological Macromolecules, vol. 107, no. Part B, pp. 1898-1907, 2018.

[8] Y. Yu, M. Shen, Z. Wang, Y. Wang, M. Xie, and J. Xie, "Sulfated polysaccharide from _Cyclocarya paliurus_ enhances the immunomodulatory activity of macrophages," Carbohydrate Polymers, vol. 174, pp. 669-676, 2017.

[9] Z. Yang, J. Wang, J. Li et al., "Antihyperlipidemic and hepatoprotective activities of polysaccharide fraction from _Cyclocarya paliurus_in high-fat emulsion-induced hyperlipidaemic mice," Carbohydrate Polymers, vol. 183, pp. 11-20, 2018.

[10] Z. Yang, J. Zhao, J. Wang, J. Li, K. Ouyang, and W. Wang, "Effects of _Cyclocarya paliurus_ polysaccharide on lipid metabolism-related genes DNA methylation in rats," International Journal of Biological Macromolecules, vol. 123, pp. 343349, 2019.

[11] Z. W. Yang, K. H. Ouyang, J. Zhao, H. Chen, L. Xiong, and W. J. Wang, "Structural characterization and hypolipidemic effect of Cyclocarya paliurus polysaccharide in rat," International Journal of Biological Macromolecules, vol. 91, pp. 1073-1080, 2016.

[12] Y. Jin, Z. Jin, and S. Jiang, "Antiproliferative and proapoptotic effects of Cyclocarya paliurus polysaccharide and X-ray irradiation combination on SW480 colorectal cancer cells," Molecular Medicine Reports, vol. 20, no. 4, pp. 35353542, 2019.

[13] F. Zhang, B. Fan, and L. Mao, "Radiosensitizing effects of Cyclocarya paliurus polysaccharide on hypoxic A549 and H520 human non-small cell lung carcinoma cells," International Journal of Molecular Medicine, vol. 44, no. 4, pp. 1233-1242, 2019. 
[14] Z. Wu, T. Gao, R. Zhong et al., “Antihyperlipidaemic effect of triterpenic acid-enriched fraction from Cyclocarya paliurus leaves in hyperlipidaemic rats," Pharmaceutical Biology, vol. 55, no. 1, pp. 712-721, 2017.

[15] C. Jiang, Q. Wang, Y. Wei et al., "Cholesterol-lowering effects and potential mechanisms of different polar extracts from Cyclocarya paliurus leave in hyperlipidemic mice," Journal of Ethnopharmacology, vol. 176, pp. 17-26, 2015.

[16] J. H. Xie, X. Liu, M. Y. Shen et al., "Purification, physicochemical characterization and anticancer activity of a polysaccharide from Cyclocarya paliurus leaves," Food Chemistry, vol. 136, no. 3-4, pp. 1453-1460, 2013.

[17] Y. Hou, X. Ding, W. Hou et al., "Pharmacological evaluation for anticancer and immune activities of a novel polysaccharide isolated from Boletus speciosus Frost," Molecular Medicine Reports, vol. 9, no. 4, pp. 1337-1344, 2014.

[18] C. Wang, S. Shi, Q. Chen et al., "Antitumor and immunomodulatory activities of Ganoderma lucidum polysaccharides in glioma-bearing rats," Integrative Cancer Therapies, vol. 17, no. 3, pp. 674-683, 2018.

[19] B. W. Doble and J. R. Woodgett, "GSK-3: tricks of the trade for a multi-tasking kinase," Journal of Cell Science, vol. 116, Part 7, pp. 1175-1186, 2003.

[20] C. A. Grimes and R. S. Jope, "The multifaceted roles of glycogen synthase kinase 3beta in cellular signaling," Progress in Neurobiology, vol. 65, no. 4, pp. 391-426, 2001.

[21] S. Kotliarova, S. Pastorino, L. C. Kovell et al., "Glycogen synthase kinase-3 inhibition induces glioma cell death through c-MYC, nuclear factor- $\kappa \mathrm{B}$, and glucose regulation," Cancer Research, vol. 68, no. 16, pp. 6643-6651, 2008.

[22] D. J. Mulholland, S. Dedhar, H. Wu, and C. C. Nelson, "PTEN and GSK3 $\beta$ : key regulators of progression to androgenindependent prostate cancer," Oncogene, vol. 25, no. 3, pp. 329-337, 2006.

[23] G. P. Yang and L. F. Lau, "Cyr61, product of a growth factorinducible immediate early gene, is associated with the extracellular matrix and the cell surface," Cell Growth \& Differentiation, vol. 2, no. 7, pp. 351-357, 1991.

[24] D. Xie, D. Yin, H. J. Wang et al., "Levels of expression ofCYR61andCTGFAre prognostic for tumor progression and survival of individuals with gliomas," Clinical Cancer Research, vol. 10, no. 6, pp. 2072-2081, 2004.

[25] R. Donnellan and R. Chetty, "Cyclin D1, and human neoplasia," Molecular Pathology, vol. 51, no. 1, pp. 1-7, 1998.

[26] L. Ma and J. Li, "MicroRNA-519d-3p inhibits cell proliferation and cell cycle G1/S transition in glioma by targeting CCND1," Bioscience, Biotechnology, and Biochemistry, vol. 84, no. 2, pp. 297-304, 2019.

[27] A. Satelli and S. Li, "Vimentin in cancer and its potential as a molecular target for cancer therapy," Cellular and Molecular Life Sciences, vol. 68, no. 18, pp. 3033-3046, 2011.

[28] X. Liu, S. Min, N. Wu et al., "miR-193a-3p inhibition of the Slug activator PAK4 suppresses non-small cell lung cancer aggressiveness via the p53/Slug/L1CAM pathway," Cancer Letters, vol. 447, pp. 56-65, 2019. 